\title{
Psychological Types of the Human Race.
}

A $\mathrm{T}$ the anniversary meeting of the Royal AnthropoA logical Institute held on January 22, Prof. C. G. Seligman delivered his presidential address, in which he discussed some possible developments of anthropological interest arising out of the views put forward by Jung concerning the importance of the two "types" which he calls extravert and introvert. Although Jung reached his conception by a consideration of the contrast in their reactions to the external world of sufferers from two pathological conditions, hysteria and dementia præcox, there is evidence that their peculiarities are not simply the product of illness, but that dissociations or eccentricities are known to have occurred in a large number of patients before the development of the disease. Again, although Jung was spoken of as the discoverer of the two types, this is not literally true, for years before, the soundest of observations had been made upon the two types by Henry James, who described them as "the tender-minded" "introvert] and "the tough-minded " [extravert]. Nevertheless it was Jung who first pointed out their practical importance.

The art products of the two types among the white races were then examined. Following Thornton. and Gordon it was shown that when well marked, the two types produce different styles of painting. This is illustrated by considering the typical pictures of the following painters, Rubens, Delacroix and Signac, extravert, as against Poussin, Ingres and Marchand, introvert. Further, two styles of poetry apparently agreeing with the two "types" can be defined, while it was suggested that a critic sufficiently cognisant with plastic art would probably find that here too the difference existed.

The more direct biological questions connected with the two types were then considered. It was suggested that they occur in about equal numbers, though extraverts, being more adapted to the world and generally more immediately responsive, give the impression of being in the majority. Although both extraverts and introverts occur in the same family, the condition of any individual must be taken as innate, and the examination of a relatively small number of instances suggests that where alternate inheritance of physical characters (skin, hair) occurs, there may be a tendency to a correlated inheritance of type.

Applying the type question to savages, it is suggested that, compared with Northern Europeans, all or nearly all savages will be found to be extravert, though the degree of extraversion varies immensely. Thus while no one would doubt that Papuo-Melanesians and Veddas (the latter with their extreme tendency to dissociation) are almost extreme examples of extraversion, the Dinkas of the Upper Nile, with their utter lack of interest in the white man and his contrivances, their absence of desire for clothes and trade objects, with their extreme religiosity: their customary gravity and aloofness, are relatively introvert, contrasting strongly with such peoples as the Azandeh and presumably the West African negroes. The character of chiefs raises some interesting questions. In some instances-especially in the case of kings uniting temporal and spiritual authority-the chiefs are even more extravert than their commoners; this opinion is based on the frequency and ease with which dissociation occurs during religious ceremonies in which they are protagonists.

There was little time left to discuss the more civilised people of the far East, but it was pointed out that while old speculative India with its mystical habits of religion and philosophy is undoubtedly introvert, Japan-as illustrated by the writings of its best known official apologists-is extravert, while China-again on the evidence of its own literature -is very largely introvert.

With regard to dreams, Prof. Seligman pointed out that the dream mechanism of non-Europeans, whether savages or barbaric, seems to be the same as in ourselves. Dreams with symbolism, sometimes elaborate and recondite, often simple and obvious, occur, and these may be wish fulfilments or be provoked by conflict. Moreover, among the peoples investigated, dreams seem to be interpreted on much the same lines as among ourselves, e.g. either conventionally (often by opposites) or by association, i.e. by an elementary self-conducted analysis. At the present time the greatest interest appears to attach to those dreams with the same manifest content to which identical meanings are given (type dreams), occurring not only among individuals of the same stock, but also among peoples of diverse races and in every stage of culture. Among such dreams the tooth-losing dream and the flying dream offer particularly good instances of wide distribution. They are, indeed, found alike in Africa and over the greater part of the Eurasian land mass among peoples between whom it is difficult to believe that any passing on of the meaning of these dreams can have occurred.

\section{Population and Longevity.}

PROFS. RAYMOND PEARL and Lowell Reed have recently published in Metron (vol. 3, 1923) a paper on "The Mathematical Theory of Population Growth." This is a more detailed account of the method already described in two papers which appeared in the Proceedings of the U.S. National Academy of Sciences in June 1920 and December I922.

The method originally suggested was the use of the equation,

$$
y=\frac{b e^{a x}}{\mathrm{I}+c^{a x}}
$$

where $y$ is the population at any time, $x$ is the time in years since the definite origin, and $a, b$, and $c$ are positive values. This was found, when tested on the known population growth of the United States since I 790 , to give a very good fit as a first approximation and a better graduation than the parabolic or log- arithmic parabolic equation. Later, the method was extended and developed and a more general formula devised, namely,

$$
y=\frac{k}{\mathrm{I}+m e^{a_{1} x+a_{2} x^{2}+a_{3} x^{3}} .}
$$

This formula is an advance on the other in that it is more flexible and provides for asymmetry.

Profs. Pearl and Reed have made use of the latter formula in an investigation into the probable growth of the population of New York and its environs during the next 80 years. They estimate that in A.D. 2000 the total population of the region will have in. creased from 9,000,000 to $29,000,000$, an increase of three times the present population. The negro population will have trebled itself and will then constitute 5 per cent. of the population. With the exception of the foreign-born section the population will have attained in A.D. 2000 almost the point of stabilisation.

$$
\text { NO. } 2835 \text {, VOL. I I } 3 \text { ] }
$$

